A unique and fundamental characteristic of malignant neoplastic cells is their ability to invade other tissues and metastasise. The first step in this process is the dissociation of some of these cells from the tumour invasion front, named tumour budding (TB). This phenomenon has become increasingly relevant in recent years due to its association with adverse clinicopathological characteristics and with the epithelial-mesenchymal transition. TB has been studied by mixing colon with rectal tumours, but it is clinically important to differentiate these types of tumours. A review in two databases without language restriction was performed from 1950 to 2017 about TB with an emphasis on rectal cancer. We present various aspects of TB, from its terminology and evaluation to its molecular aspects, through its clinical associations. TB is associated with adverse clinicopathological features, like lymphovascular invasion, lymph node metastasis, and decreased survival. More studies of the clinicopathological, molecular, and epidemiological characteristics of TB in rectal cancer are needed.

Key words: colorectal cancer, tumour budding, epithelial-mesenchymal transition, prognosis, cancer.

Contemp Oncol (Pozn) 2018; 22 (2): 61-74 DOI: https://doi.org/10.5114/wo.2018.77043

\section{Tumour budding in rectal cancer. A comprehensive review}

\author{
Leonardo S. Lino-Silva ${ }^{1}$, Rosa A. Salcedo-Hernández ${ }^{1}$, \\ Armando Gamboa-Domínguez ${ }^{2}$
}

${ }^{1}$ National Cancer Institute, Mexico City, Mexico

${ }^{2}$ National Institute of Medical Sciences and Nutrition, Mexico City, Mexico

\section{Introduction}

A unique and fundamental characteristic of malignant neoplastic cells is their ability to invade new tissues and metastasise. The first step in this process is the dissociation of some of these cells from the invasive front of the tumour, which is often associated with a transformation: either dedifferentiation or transdifferentiation. Several researchers have highlighted the histopathologic representation of this phenomenon using various terms, but the most accepted is tumour budding (TB), which has become relevant recently given TB's relationship with vascular invasion, metastasis, and prognosis in colorectal cancer [1-18]. In addition, it has been hypothesised that TB is a morphologic representation of the epithelial-mesenchymal transition (EMT) [19].

Most of the literature on this phenomenon has focused on colorectal carcinoma (CRC) as a single entity because both sites share characteristics and prognostic factors; however, several of these characteristics behave differently in colon tumours than in rectal tumours, so it is advisable that the two sites be analysed separately. For this review, we searched all the literature available about TB in CRC from 1950 to 2017 using the databases Medline and EMBASE without language restriction. In addition, we also used papers that were missed in the search but listed in the reference lists of the obtained papers. For the historical, subcellular, morphological aspects and histological evaluation, we used works carried out in CRC; for associations with clinical outcomes, only articles about rectal cancer were described.

\section{Historic evolution}

The term TB is not new; it was first reported almost 70 years ago in Japan. The first mention was made by Imai [1], when he proposed the "CPL staging system" for cancer based on three parameters: 1) the "sprouting" (what we know today as TB) of tumour cells (C), 2) peritumoural stromal reaction (P), and 3) lymphovascular invasion ( $\mathrm{L}$ ). These observations were later reported to be useful in CRC [2-3]. Despite these first reports, these concepts disappeared from the literature until the 1980s, when it was reported that TB was strongly associated with lymph node metastases in gastric carcinoma and early CRC [4-7]. Later, during the 1990s, Hase et al. [8] demonstrated the association of TB with adverse clinicopathological factors such as tumour grade, tumour stage, and lymphovascular and perineural invasion, as well as laying the groundwork for the evaluation of TB. During the following years, little was studied until the middle 2000s, when a few studies about the morphological and molecular aspects of TB were published, expanding the knowledge about TB to other carcinomas such as breast, lung, oesophagus, and pancreas.

\section{Tumour budding definition}

Tumour budding definition has been a controversial issue throughout its development, and even nowadays, when there is a consensus about it [9]. 
Some researchers have defined TB as the presence or absence of single cells around a tumour invasive front, while others authors have counted them as the number of buds on the invading front, while several others have counted them as the number of buds on the intra-tumoural stroma, etc. [1-8]. Tumour budding cells are individual cells or small groups of up to four or five elements separated from their counterparts in the bulk of the main tumour (Fig. 1). The definition most widely used and adopted in the consensus is that TB is an isolated tumour cell or those in groups of up to four cells separated from the glands of the tumour invading front (Table 1 and Appendix 1) [9].

\section{Grading tumour budding}

Several of the first classifications of the TB were subjective, such as those of Hase et al. [8], who presented a two-level system comparing none or "minimal" vs. "moderate" or "severe". Goldstein et al. [10] determined TB as absent or focal when there were $<3$ "focus of budding", moderate when there were 2 to 10 foci or a linear extension of $<3 \mathrm{~mm}$, and extensive when there were $>10$ foci or had an extension $>3 \mathrm{~mm}$. Nakamura et al. [11] proposed a four-level method (none, mild $<1 / 3$, moderate $1 / 3$ to $2 / 3$, and severe $>2 / 3$ ). These systems are subjective and were used in a few works [12-15].

The first quantitative method was proposed by Morodomi [6], where it is simply qualified as present ( $\geq 1$ tumour bud for high-power field) or absent. This method is widely used because of its practicality and good interobserver concordance (kappa index [ $\kappa], \kappa=0.938$ ) [16]. Ueno et al. $[17,18]$ proposed two quantitative methods based on the hot spot of the TB using a microscopy lens of $20 x$ magnification in one observation field (accounting for an area of $0.785 \mathrm{~mm}^{2}$ ) or of $25 \times$ (area of $0.385 \mathrm{~mm}^{2}$ ), which are perhaps the most widely used methods (Table 1 ) with some variation in both the cut-off point to set up the prognostic groups and in the evaluation area.

Wang et al. [20] presented a method based on the selection of five random areas of $0.95 \mathrm{~mm}^{2}$ and the subsequent evaluation of each area for the presence of any bud.
A positive case would be one where there is $\geq 50 \%$ of the areas with at least one bud, but this method has not been replicated.

Finally, one study determined that the median time per slides evaluating five fields in an area of $0.945 \mathrm{~mm}^{2}$ ranged from 1.3 to 1.7 minutes (range of 0.4 to 2.7 minutes). Using a rapid count method and scoring the TB as presence vs. absence, the median time for evaluation ranged from 0.49 to 0.83 minutes (range 0.3 to 1.7). The difference between the first method and the rapid count was significant $(p<$ 0.001) [20].

\section{Reproducibility of the determination of tumour budding}

The minimum requirements for an ideal prognostic parameter are its reproducibility, availability, and quality control. Also, the system categories must have a real predictive value beyond the recognised prognostic systems. Studies addressing reproducibility have shown that it varies much, probably reflecting differences in the definition and quantification method of TB. Ueno et al. [18] demonstrated a substantial agreement between observers ( $\kappa=$ 0.646) when patients were stratified into four groups according to the degree of TB; however, the level of concordance improved using stratification into one of two groups $(\kappa=0.84)$. Zlobec et al. [21], during a classification into two grades, found a $\kappa$ of 0.6. Okuyama et al. [22], in a classification based on two categories (absence versus presence of TB), found an excellent concordance ( $\kappa=0.938$ ); however, using the same classification, the studies of Hörkkö et al. [23] and Wang et al. [20] found a $\kappa$ of 0.760 and 0.51 , respectively.

The use of immunohistochemistry (IHC) with cytokeratin allows the easy identification and rapid classification of TB and improves reproducibility (Fig. 2). Prall et al. [24] evaluated tumour budding with IHC using cytokeratin and reported a good intra-observer agreement with a $\kappa$ of 0.874 , Karamitopoulou et al. [25] demonstrated an interobserver agreement of 0.5 to 0.87 depending on the method and the number of observers. In two studies, the interobserver con-
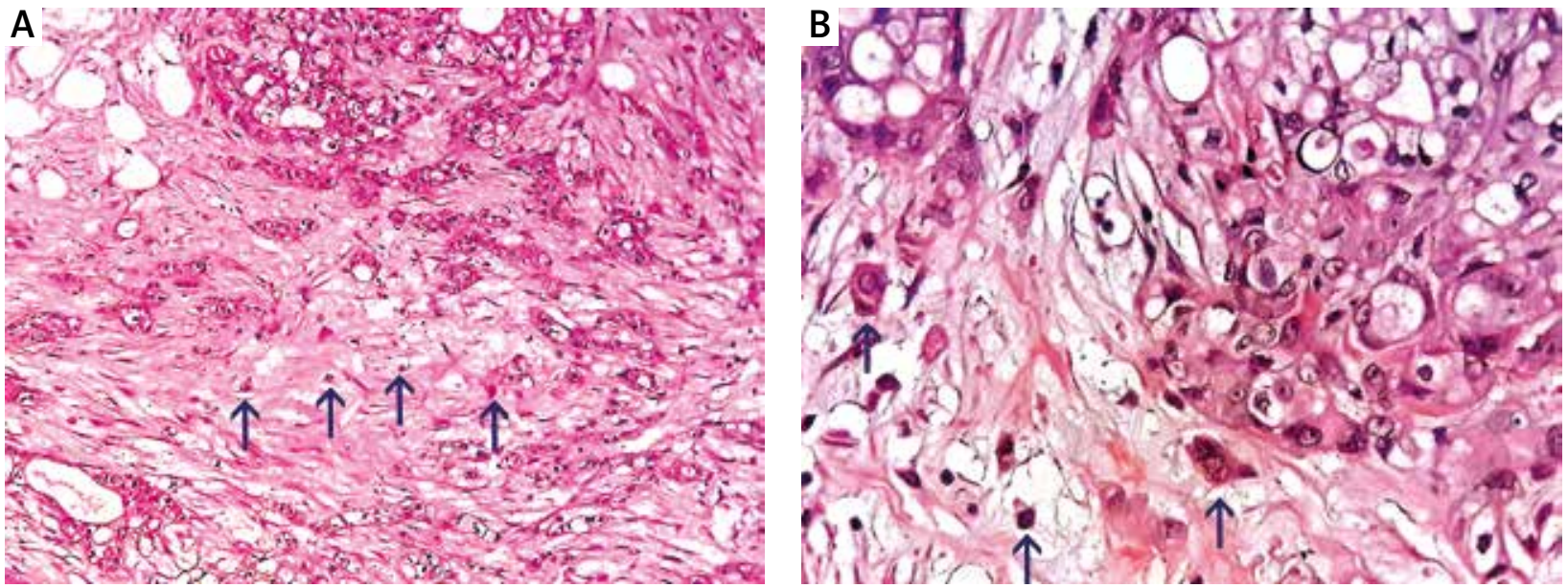

Fig. 1. A) Morphology of tumour budding. Note several individual cells (tumour budding cells, arrows) are detached along the infiltrative margin of the tumour. Haematoxylin and eosin, 40x. B) Several neoplastic cells infiltrating the stroma (arrows) in individual units are observed. Haematoxylin and eosin, 400x 


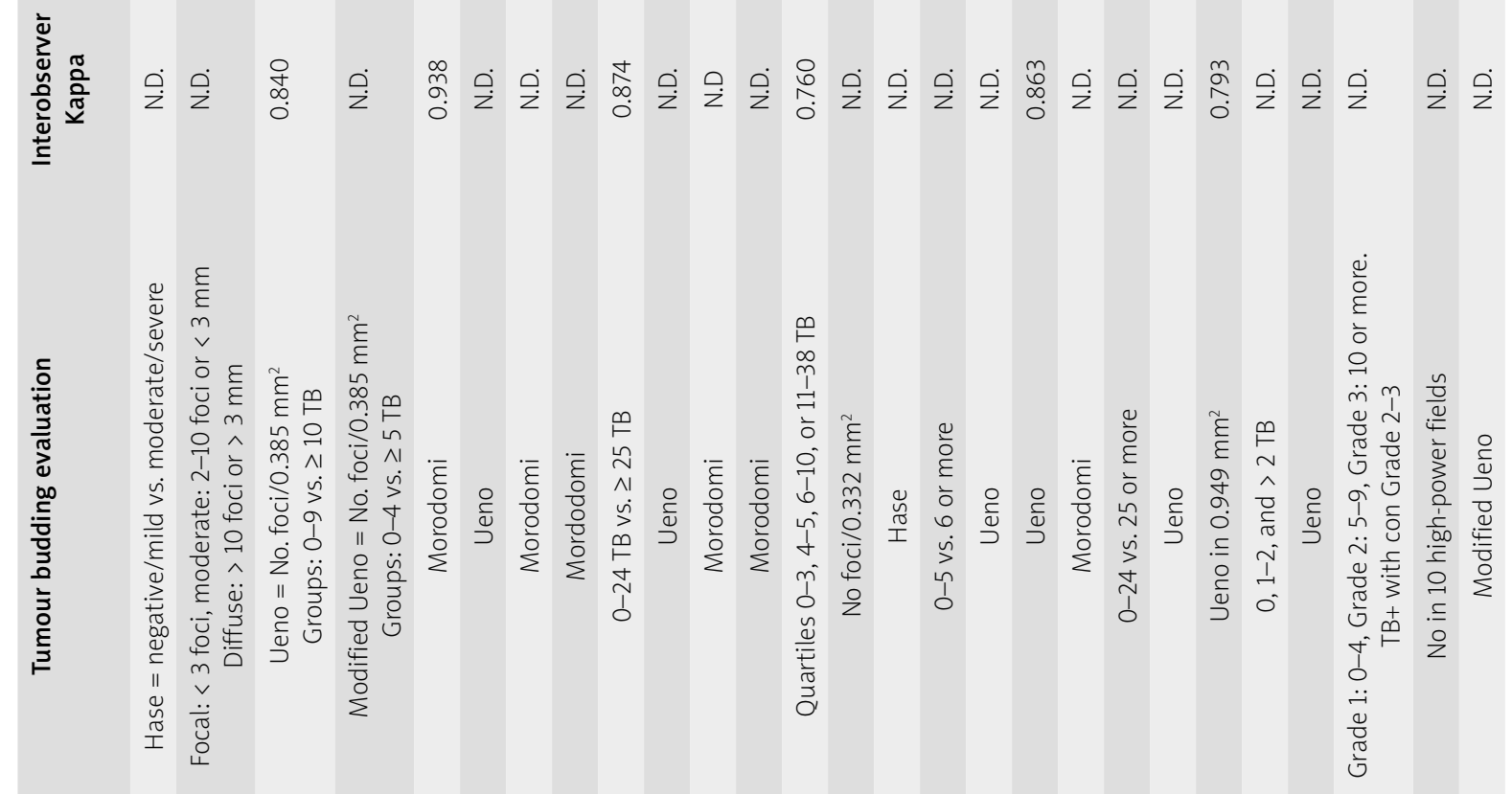

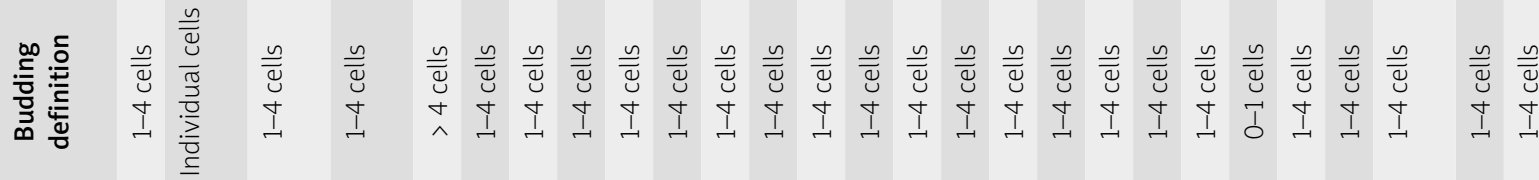

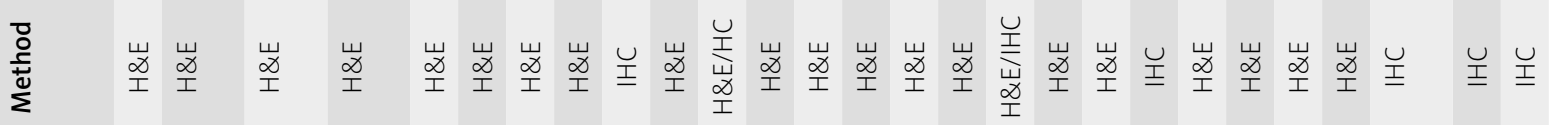

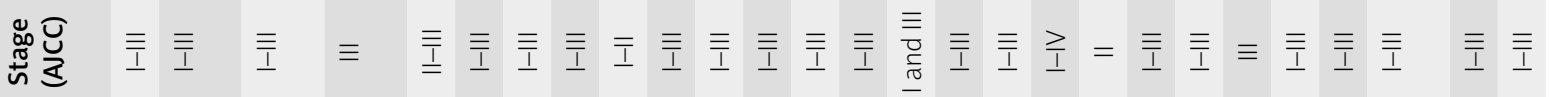

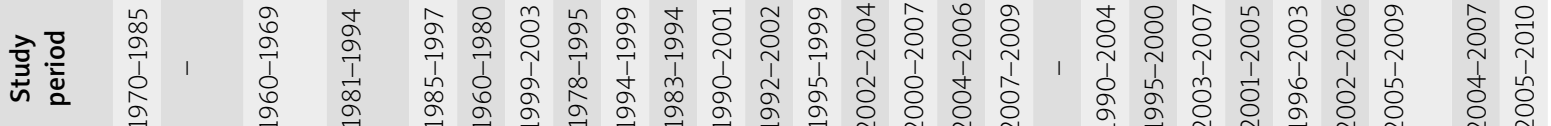

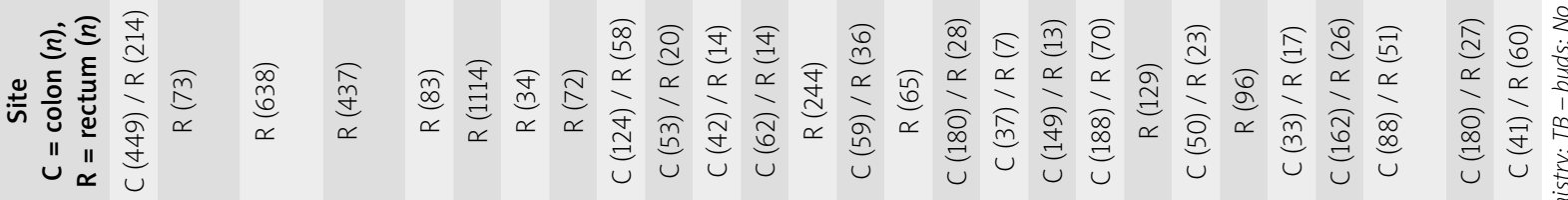

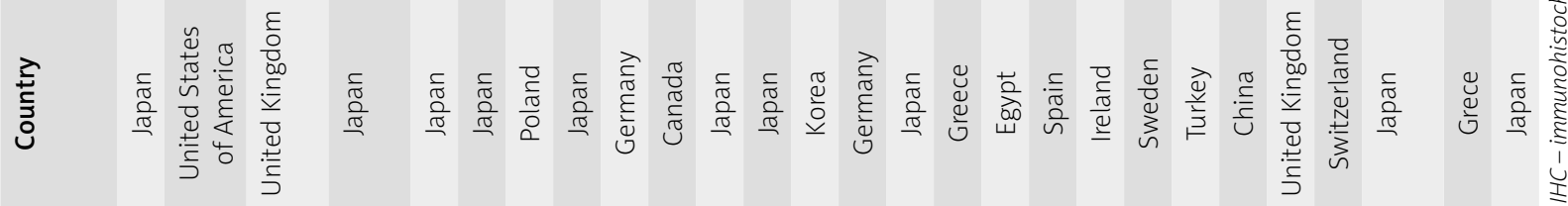
ลิ

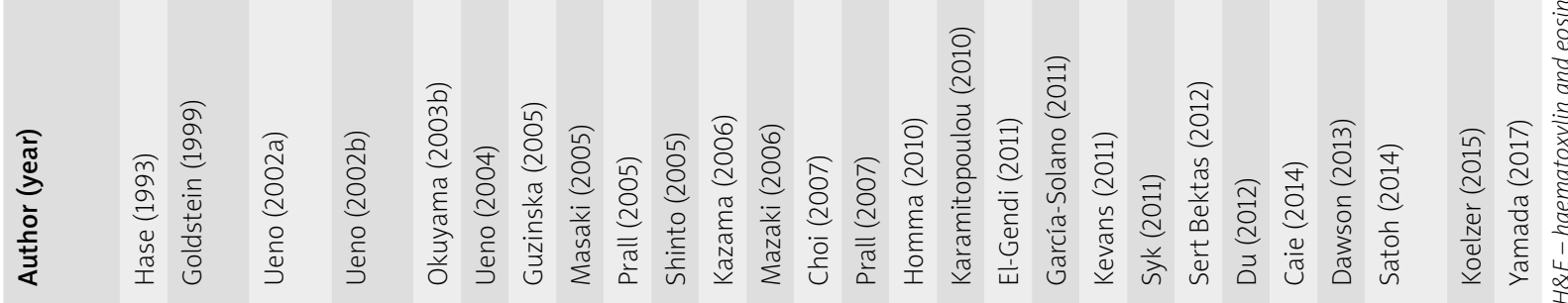


cordance between haematoxylin and eosin (H\&E) and IHC were specifically evaluated, and an improved $\kappa$ from 0.41 to 0.53 [26] and from 0.33 to 0.42 [27] was found with the use of $\mathrm{IHC}$, in addition to demonstrating that $\mathrm{IHC}$ assessment is better for less experienced pathologists. Similarly, Ohtsuki et al. [28] found that the detection and evaluation of TB by $\mathrm{IHC}$ is an independent prognostic factor for recurrence. Rieger et al. [29] found that the evaluation of TB with IHC in a single hot spot had a similar diagnostic performance when compared with the evaluations in 10 fields, which suggests that it is more practical. Conversely, Okamura et al. [30] found that the evaluation of TB by H\&E was a significant predictor of lymph node metastasis, while the detection by IHC was not. Finally, several works comparing different methods of grading TB showed that interobserver reproducibility is highly variable depending on the cut points, the number of categories, the number of observers, and the method used (H\&E, IHC, using software, and telepathology) [31-33].

\section{Morphology of tumour budding}

It has been determined that TB is made up of individual cells or small groups of cells (Fig. 1) [18, 19, 25]. Although the morphology of TB suggests an energetic migration of cells identified as whole cells or small cytoplasmic fragments, it actually appears that TB consists of a migration of projections originating in solid structures or glands of the invading front, conformed by cellular aggregates of even a size superior to the four or five cells under the definition of TB $[34,35]$. These projections are well-organised with a basal lamina that abuts the outer circumference; they have intercellular junctions and microvilli (abortive) as well as an envelope of myofibroblasts. This shows that the neoplastic gland is invading, advancing through long extensions like dendritic extensions, called "podias" [35-37] or "tubular invasion pole" [38], a fact that has been well demonstrated in studies that have made serial sections of the tumour [39].

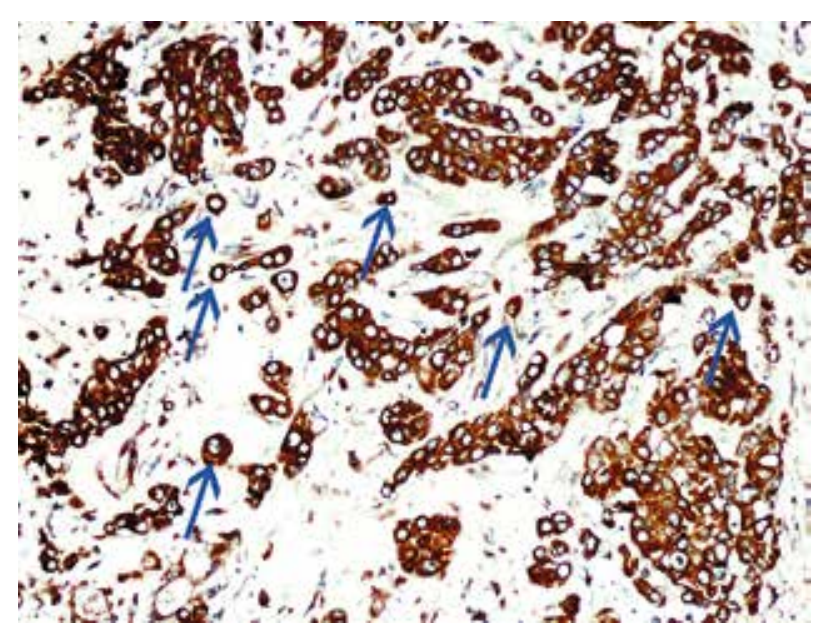

Fig. 2. Immunohistochemistry with cytokeratin cocktail highlights tumour budding cells (blue arrows) and allow to evaluate the TB more rapidly and easily. CKAE1/AE3 contrasted with haematoxylin, $100 \times$
However, this organised state seems to be focally disturbed: myofibroblasts may be withdrawn or absent, ultra-structurally, there is an absence of basal lamina, and the cytoplasmic junctions of the tumour cells come into direct contact with the extracellular matrix (i.e. the intercellular junctions are lost) [40]. Despite these findings, it has also been observed through experimental models and with $3 \mathrm{D}$ reconstruction that there is indeed a true migration of individual cells from the main body of the tumour to the stroma, and it has been calculated that the theoretical proportion of individual cells is $0.003 \%$ [41].

\section{Association of tumoural budding with histopathological characteristics of rectal carcinoma}

In rectal cancer, the definition of high-risk TB depends on the study, but generally corresponds to the presence of $>10$ buds per unit area and has been identified between $30.1 \%$ [18] and 92\% [42]; it is associated with pathological characteristics such as poor tumour differentiation, pathological stages T3 and T4, lymph node metastases (both the total number and the tumour volume), less lymphocyte infiltration, and greater frequency of lymphatic and venous vascular invasion [10, 18, 22, 43, 44]. There has no histopathological subtype associated specifically with highgrade tumour budding; indeed, the TB evaluation should be performed in any histologic subtype, especially in the conventional tubular subtype [9].

\section{Inflammation}

Several studies have shown that lymphocytes within the tumour stroma (intratumoural lymphocytes - ITL) and around the tumour along the invasive margin (peritumoural lymphocytes) are significantly related to the best overall and disease-specific survival in multivariate analyses [45-47].

It has been shown that TB is inversely correlated with the infiltration of CD8+ T cells, suggesting a possible defence, based on T cells, against the infiltration of TB cells in the tumour microenvironment of the CCR [48]. Once the tumour buds are formed, they are able to evade the immune response of the host directed by the CD8+ T cells, in addition to the loss of Major Histocompatibility Complex-I (MHC-I) expression identified in these cells [33], which supports the notion that immune evasion by the primary tumour can ease the invasion process. Conversely, the same authors demonstrated that patients capable of developing a functional immune response that includes the activation of CD8+ T cells and the expression of TIA1 cytotoxic granule-associated RNA binding protein (TIA1) may be able to destroy cancer cells that express MHC-I on the invasive front. These authors found an almost complete absence of budding cells in the tumour stroma of cases with increased expression of CD8+ and TIA1+ in the stroma as well as MHC-I in the invading front. Finally, two studies show that the density of the inflammatory infiltrate correlates proportionally with a better prognosis and a lower degree of TB $[49,50]$. 


\section{Tumour regression}

Very few studies had addressed the significance of TB in preoperative biopsies of patients receiving preoperative chemoradiotherapy. Lugli et al. [51] found that patients with a high degree of TB showed an increased rate of pathological complete response compared with patients with lower degree of TB. We also confirmed this finding in a series of 216 cases, in which patients with low degree were associated with more pathologic complete response (odds ratio 2.52 , 95\% confidence interval $(95 \% \mathrm{Cl})=1.366$ 4.894, $p=0.025$, manuscript under review). The evaluation in biopsies is well-designed "intratumoural budding" and has been associated with the same adverse clinicopathological features that a high degree of TB in both colon and rectum [51], unfortunately, it was not considered in the TB consensus [9].

\section{Microsatellite instability}

Tumour budding is very rare in cancers that have a deficiency of DNA mismatch repair proteins (MMR) [51-53]. Colorectal cancers with microsatellite instability (MSI) have more ITL, more peritumoural lymphocytes, and more peritumoural lymphoid aggregates when compared to stable CRC in microsatellites. These factors contribute to the lower occurrence of TB in the CRC with MSI [51, 52].

\section{Tumour budding and prognosis in rectal carcinoma}

The association of high TB with a decrease in overall survival has been demonstrated in studies of stages I to III that did not receive preoperative treatment with chemotherapy or radiotherapy. Ueno et al. [18] found a five-year overall survival of $84 \%$ in patients with $<10$ tumour buds compared to $40.7 \%$ in those who had $\geq 10$ ( $p=0.0001$ ), and in the multivariate analysis, they found an odds ratio for the deaths of $18.49(95 \% \mathrm{Cl}=1.45-2.68, p<0.0001)$. Okuyama et al. [22] also found a lower five-year survival in patients with high TB (51.8\% vs. $85.0 \%, p<0.002)$. In a sub-analysis, the stage II showed a five-year survival of $71.3 \%$ vs. $89.7 \%$ ( $p<0.03$ ), and stage III showed $37.8 \%$ vs. $62.5 \%(p=0.396)$. In the multivariate analysis, they found an odds ratio for the death of $2858(95 \% \mathrm{Cl}=1.121-7.287$, $p<0.03$ ). Furthermore, Choi et al. [42] found a five-year survival of $76.7 \%$ for patients with $\leq 10$ buds compared to $47.2 \%$ for those with $>10$ buds ( $p<0.0001)$. On the other hand, Du et al. [54] studied patients in stage III post chemo-radiotherapy and found that patients with grades 2 and 3 of Ryan's tumour regression stage had a worse fiveyear survival in the group with high-TB (55.6\% vs. $87.5 \%$, $p<0.001$ ), and in the multivariate analysis, the absence of TB was associated with a lower risk of death $(\mathrm{OR}=0.177$, $95 \% \mathrm{Cl}=0.069-0.454, p<0.001)$. However, Bhangu et al. [55] found no association of TB with survival in patients with preoperative chemo- and radiotherapy. Finally, high TB has been associated with higher recurrence rates [42, $56,57]$.

\section{Molecular characteristics of tumour budding}

Tumour budding cells show properties similar to stem cells - similar to even the gastrulation process within embryogenesis - including the potential to re-differentiate both in the primary tumour and in metastatic sites [58]. It is also suggested that their phenotypic and morphological characteristics are dynamic and reversible due to epigenetic control.

The epithelial cells are normally contained within the basal membranes of the glandular structures called the "capsule" by some authors [39]. The focal degeneration of the capsule, due to age or disease, attracts lymphocytes that degrade them, resulting in a focal rupture. If the epithelial cells that cover the defect have terminal differentiation, there will be no cell division; this will be minimal, or the basement membrane will be repaired. However, if focal disruption occurs in a region of the basement membrane where the progenitor cells and/or tumour stem cells are, these cells have the opportunity to proliferate, causing their "budding" through the defect and later growth in the surrounding stroma [59-61]. Once proliferating epithelial buds are formed, their interaction with lymphocytes leads to an early pathway for metastasis. These observations were made in breast and prostate cancer tissues, where the epithelial cells are surrounded not only by a basement membrane but also by a well-organised layer of myoepithelial cells. This layer of cells exists in the rectal crypts; however, not enough attention has been paid to it [62].

As the lymphocytes infiltrate the tumour buds, they disrupt intercellular junctions and surface adhesion molecules, facilitating the dissociation of some cells and favouring TB. During this process, lymphocytes and tumour cells can form stable pairings (called tumour lymphocyte chimeras) through simple membrane fusion that does not trigger phagocytosis or the destruction of tumour cells [63]. This fusion can be mediated by the binding of the antigen associated with the lymphocyte expressed in immune cells and integrins in tumour cells [64]. A theory about metastasis is that this coupling allows the tumour cells to take advantage of the natural ability of the lymphocyte to migrate and break down cellular barriers to invade and travel to distant organs where the pair may then extravasate and grow [64].

\section{Loss of intercellular adhesion and the epithelial- mesenchymal transition}

The $\beta$-catenin protein, a membranal intercellular adhesion protein, has been implicated in the development of TB. It accumulates in the nucleus of the CRC cells of the invasive front, especially in undifferentiated or mesenchymal cells [47, 65-68]. This accumulation leads to the activation of the Wnt signalling pathway and other oncogenic events [69] in cells that are positive to CD44 [65] and laminin $5 \gamma 2$ [12]. However, the TB process is largely restricted to the invasive margin, where the interaction between the malignant epithelium and the stromal elements occurs, suggesting that a TB phenotype is also driven by growth signals derived from mesenchymal cells $[20,52]$. 
Several authors investigating the invasive front of CRC have used the term epithelial-mesenchymal transition (EMT), which characterises tumour invasion by dedifferentiated colorectal carcinoma cells. This process, which occurs physiologically during embryological development (EMT type I), has also been associated with tissue reparation (EMT type II) and tumour invasion (EMT type III). The cells in EMT lose their epithelial phenotype and acquire a mesenchymal phenotype (acquiring a fusiform morphology, they become mobile and begin to express markers including fibronectin and vimentin) [70-73] as well as lysosomal proteases such as cathepsin D and B [74]. Cathepsin D, as an endopeptidase, degrades many intracellular and endocytosed proteins as well as extracellular matrix (ECM) and basal epithelial proteins [75]. Cathepsin B often increases specifically in the invasive border of the carcinoma where the granules containing cathepsin B are located on the internal basal surface of the plasma membrane of neoplastic cells, contrary to normal cells that are located perinuclearly [76]. Degradation of the ECM is a very important step for tumour progression because the invasion of tumour cells implies a local proteolysis. Matrix metalloproteinase-9 (MMP-9) and metalloproteinase-2 (MMP-2) play a similar role, and it is suggested that the degradation of the basal membrane and the ECM by cathepsins and MMP-9 at the site of infiltration is the first stage of cancer invasion [77, 78]. Emmert-Buck et al. [79], who used a microdissection technique to determine the levels of enzymatic activity in specific microscopic areas of human colon cancer, found that gelatinase A and cathepsin B activities were positively regulated in the invasion fronts of invasive colon tumours.

Despite the postulations described before, the EMT in CRC cells has not been well demonstrated.

\section{Tumour budding and DNA integrity}

Microsatellite instability is associated with a high-level CpG island methylation phenotype (CIMP-H), which can occur in up to $40 \%$ of cancers, and both MSI and CIMP-H often share clinicopathological and molecular features such as tumour localisation, poor differentiation, BRAF mutation, and possibly an increase of ITL CD8+ [80]. Although, typically, patients with MSI tumours have fewer metastases and benefit from a prolonged survival time, the prognosis for patients with $\mathrm{CIMP}-\mathrm{H}$ tumours is often poor. One hypothesis to explain this apparent contradiction is that CIMP-H could promote a high-grade TB phenotype. Also, CIMP-H has been linked to the methylation of O6-methylguanine-DNA methyltransferase (MGMT), a gene that acts to repair inappropriately methylated guanine residues in DNA. The hypermethylation of the MGMT promoter occurs as an early event in colorectal carcinogenesis and is part of the alternative route of tumourigenesis that begins with the mutation of adenomatous colonic polyposis, a trigger of the EMT that causes activation of the Wnt pathway, the nuclear translocation of $\beta$-catenin, and the loss of E-cadherin (all characteristics of the high-grade TB phenotype) [81].

\section{Tumour budding and other genes}

In CRC cells, RAS signalling is important for EMT. The normal non-mutated RAS proteins are active in response to growth factors that bind to tyrosine kinases of the membranous receptor. In a signalling cascade involving the phosphorylation of extracellular mitogen-activated kinases, the signal is transmitted to the nucleus where it activates the transcription factors that influence the control of cell division (e.g. c-Jun, c-Myc, c-Fos). Alternatively, RAS activated through phosphoinositol 3-kinase (PI3K) acts on the actin filaments within the cells. Accordingly, processes as diverse as cell proliferation and modulation of cell shape and cell migration are stimulated by RAS-mediated signalling. In CRC, the gene is known to contain activating point mutations in $30 \%$ of the tumours $[82,83]$.

\section{Cell proliferation and cell death}

TB cells have shown low proliferation, detected by ki67 and by caspases. Rubio et al. [84] demonstrated a low ki67-index in these cells accompanied by positive regulation of cyclin D1, and p16 cell cycle arrest mediators; furthermore, genes encoding these proteins are regulated by $\beta$-catenin, and this is a mechanism of cellular arrest induced by EMT. The p16 protein acts as a direct inhibitor of cyclin D1 promoting the arrest of the cell cycle, and it has been suggested that it also binds to cyclin-dependent kinase 4 (CDK4), is required for the activation of cyclin D1, and blocks its transport to the nucleus. In the absence of CDK4, cyclin D1 forms an inactive complex with CDK2. Other factors expressed in EMT, such as transforming growth factor beta (TGF- $\beta$ ), Snail Family Transcriptional Repressor 1 (Snai1), and Zinc finger E-box-binding homeobox 1 (Zeb1), have been associated with the arrest of the cell cycle by the inhibition of cyclin D1. However, Dawson et al. [85] showed that TB cells positive for ki67 and for caspase 3 were associated with an increased risk of death (odds ratio 9.1, $p=0.023$ ).

Moreover, alterations of various proteins involved in apoptosis have been identified in TB cells. Apoptosis protease-activating factor-1 (Apaf-1) protein is a key regulator of the mitochondrial apoptotic pathway, being the central element of the multimeric complex called apoptosome, which is also formed by procaspase- 9 and cytochrome c. This protein has been identified as diminished in tumours with high TB; concomitant decrease in B-cell lymphoma 2 (BCL2) has also been identified [86-88].

It has been described that the epithelial cells detached from the surrounding extracellular matrix undergo a physiological form of programmed cell death, termed anoikis $[89,90]$. Thus, the tumour buds, as individual cells, must develop mechanisms of resistance to anoikosis if they are to survive during migration to the vessels and produce metastases. These mechanisms are complex and involve several signalling pathways that are closely related to EMT. Anoikosis avoidance could be an important factor in the biological behaviour of TB.

\section{The role of the peritumoural stroma}

The stroma seems to be a factor intimately involved with the process and maintenance of TB as well as favouring the dissemination of these cells. The role of CD10 expression in benign stromal cells has been studied in colorectal cancer [91]. It is postulated that due to the struc- 
tural similarities between CD10 and MMP, CD10 could create a microenvironment that facilitates the invasion and metastasis of cancer cells. In addition, there is a strong relationship between the expression of MMP-9 in budding cells and a more aggressive tumour phenotype [92]. In some studies, the existence of different subtypes of stromal cells has been identified in the CRC with phenotypic and functional heterogeneity [40,93].

Khanh et al. [94] found that overexpression of Mucin 1 (MUC1) cell surface-associated protein in the invasive tumour front was associated with TB and increased expression of TGF- $\beta 1$, suggesting an immunosuppressive role of MUC1. In addition, these authors found a positive correlation of MUC1 with CD10 expression in the stromal cells of fibroblastic and myeloid phenotype, suggesting that MUC1+ cells interact with stromal cells favouring the EMT process.

\section{Hypoxia and vascularisation}

TB has also been associated with hypoxia-induced hypovascularisation in the advanced front of CRC. TB cells can escape hypoxia by expressing a hypoxic tumour phenotype mediated by hypoxia-induced factor 1a (HIF-1a), which increases its malignant potential [95]. In the stroma of the invading front, increased concentrations of TGF- $\beta$, a factor that induces vasculogenesis, as well as an increase in the number of capillary vessels have also been identified [96-98]. High levels of actin, heat shock protein 47 (HSP-47), and fibroblast growth factor (FGF) have also been identified in this stroma [99].

\section{Association with miRNAs}

Three studies have investigated the association of miRNAs in CCR. In a study in patients with rectal cancer, who received preoperative chemoradiotherapy, miRNA200c decrease was detected with high TB [55]. Another study conducted in patients with stage II and III colon cancer demonstrated a decrease in miRNA200b in patients with high TB [100]. Finally, in a CRC study, patients with high TB demonstrated a decrease in miRNA148a and miRNA6253p [101].

\section{Limitations of the studies}

Many of the series reviewed are not contemporary, in an era when the imaging or molecular studies were not very developed, the material corresponded to material stored several decades ago; in many there was no ideal preoperative staging and total mesorectal excision was not the standard surgery, so there was no adequate quality control. These are important limitations of the studies. In addition, many of them correspond to selected cases and where tumour stages are combined with a different prognosis.

\section{Tumour budding in other cancers}

The prognostic significance of tumour budding in CRC has stimulated research to determine its possible influence in other cancer types. Among the most comprehensively studied cancer sites are the oesophagus [102, 103], pancreas [104-106], head and neck [107], lung [108], and breast
[109]. This research relied largely on concepts and methodologies developed in CRC studies. Consistently, in all these cancer sites, the high degree of TB has showed association with the previously discussed prognostic factors.

\section{Conclusions}

There is evidence to suggest that TB is an adverse prognostic factor that can help stratify patients into more significant risk groups. However, more studies should be done to clarify its role in rectal cancer. For the considerable prognostic power of TB to be fully accepted, consensual and reproducible criteria must be established for its evaluation and reporting. While there is a recently published consensus, this is far from ideal. There are many unanswered questions about the genesis of these cells and the underlying molecular aspects, which, once explored, will give us more information about the tumour progression in rectal cancer.

The authors declare no conflict of interest.

\section{References}

1. Imai T. Histological comparison of cancer of the stomach in autopsy and operation cases. Jpn J Cancer Res 1949; 40: 199-201.

2. Yokota K. Carcinoma of the rectum: its histological picture and its postoperative course. Igaku Kenkyu 1957; 27: 2003-2014.

3. Majima S, Karube K, Narisawa T, Takahashi T, Machida T. Clinical and pathological aspects of cancer of the colon in 193 cases-symptoms and pathological findings. Gan No Rinsho 1967; 13: 861-868.

4. Yokoyama H, Nagayo T. Initial changes in the development of gastric cancer. Gan No Rinsho 1986; 32: 250-256.

5. Hayashida K, Isomoto H, Shirouzu K, et al. A study of invasive colorectal carcinoma with reference mainly to vessel invasion and budding. Nippon Daicho-komonbyo Gakkai Zasshi 1987; 40: 119126.

6. Morodomi T. Clinicopathological studies of advanced rectal cancers predicting the degree of lymph node metastases from histopathological findings in pre-operative biopsy specimens. Nippon Geka Gakkai Zasshi 1988; 89: 352-363.

7. Morodomi T, Isomoto H, Shirouzu K, Kakegawa K, Irie K, Morimatsu M. An index for estimating the probability of lymph node metastasis in rectal cancers. Lymph node metastasis and the histopathology of actively invasive regions of cancer. Cancer 1989; 63: 539-543

8. Hase K, Shatney C, Johnson D, Trollope M, Vierra M. Prognostic value of tumor "budding" in patients with colorectal cancer. Dis Colon Rectum 1993; 36: 627-635.

9. Lugli A, Kirsch R, Ajioka Y, et al. Recommendations for reporting tumor budding in colorectal cancer based on the International Tumor Budding Consensus Conference (ITBCC) 2016. Mod Pathol 2017; 30: 1299-1311.

10. Goldstein NS, Hart J. Histologic features associated with lymph node metastasis in stage $\mathrm{T} 1$ and superficial $\mathrm{T} 2$ rectal adenocarcinomas in abdominoperineal resection specimens. Identifying a subset of patients for whom treatment with adjuvant therapy or completion abdominoperineal resection should be considered after local excision. Am J Clin Pathol 1999; 111: 51-58.

11. Nakamura T, Mitomi H, Kanazawa H, Ohkura Y, Watanabe M. Tumor budding as an index to identify high-risk patients with stage II colon cancer. Dis Colon Rectum 2008; 51: 568-572.

12. Sordat I, Rousselle P, Chaubert P, Petermann O, Aberdam D, Bosman FT, Sordat B. Tumor cell budding and laminin-5 expression in 
colorectal carcinoma can be modulated by the tissue micro-environment. Int J Cancer 2000; 88: 708-717.

13. Masaki T, Matsuoka H, Sugiyama M, Abe N, Sakamoto A, Watanabe T, Nagawa H, Atomi Y. Tumor budding and evidence-based treatment of T2 rectal carcinomas. J Surg Oncol 2005; 92: 59-63.

14. Tanaka M, Hashiguchi Y, Ueno H, Hase K, Mochizuki H. Tumor budding at the invasive margin can predict patients at high risk of recurrence after curative surgery for stage II, T3 colon cancer. Dis Colon Rectum 2003; 46: 1054-1059.

15. Kanazawa H, Mitomi H, Nishiyama Y, Kishimoto I, Fukui N, Nakamura T, Watanabe $M$. Tumour budding at invasive margins and outcome in colorectal cancer. Colorectal Dis 2008; 10: 41-47.

16. Okuyama T, Oya M, Ishikawa H. Budding as a useful prognostic marker in pT3 well- or moderately-differentiated rectal adenocarcinoma. J Surg Oncol 2003; 83: 42-47.

17. Ueno H, Murphy J, Jass JR, Mochizuki H, Talbot IC. Tumour "budding" as an index to estimate the potential of aggressiveness in rectal cancer. Histopathology 2002; 40: 127-132.

18. Ueno H, Mochizuki H, Shinto E, Hashiguchi Y, Hase K, Talbot IC. Histologic indices in biopsy specimens for estimating the proba bility of extended local spread in patients with rectal carcinoma. Cancer 2002; 94: 2882-2891.

19. Yamada N, Sugai T, Eizuka M, et al. Tumor budding at the invasive front of colorectal cancer may not be associated with the epithelial-mesenchymal transition. Hum Pathol 2017; 60: 151-159.

20. Wang LM, Kevans D, Mulcahy H, O'Sullivan J, Fennelly D, Hyland J, O'Donoghue D, Sheahan K. Tumor budding is a strong and reproducible prognostic marker in T3NO colorectal cancer. Am J Surg Pathol 2009; 33: 134-141

21. Zlobec I, Molinari F, Martin V, et al. Tumor budding predicts response to anti-EGFR therapies in metastatic colorectal cancer patients. World J Gastroenterol 2010; 16: 4823-4831.

22. Okuyama T, Nakamura T, Yamaguchi M. Budding is useful to select high-risk patients in stage II well-differentiated or moderately differentiated colon adenocarcinoma. Dis Colon Rectum 2003; 46: 1400-1406.

23. Hörkkö TT, Klintrup K, Mäkinen JM, Näpänkangas JB, Tuominen HJ, Mäkelä J, Karttunen TJ, Mäkinen MJ. Budding invasive margin and prognosis in colorectal cancer--no direct association with beta-catenin expression. Eur J Cancer 2006; 42: 964-971.

24. Prall F, Nizze $H$, Barten M. Tumour budding as prognostic factor in stage I/II colorectal carcinoma. Histopathology 2005; 47: 17-24

25. Karamitopoulou E, Zlobec I, Kölzer V, Kondi-Pafiti A, Patsouris ES, Gennatas K, Lugli A. Proposal for a 10-high-power-fields scoring method for the assessment of tumor budding in colorectal cancer. Mod Pathol 2013; 26: 295-301.

26. Suzuki A, Togashi K, Nokubi M, Koinuma K, Miyakura Y, Horie H, Lefor AT, Yasuda Y. Evaluation of venous invasion by Elastica van Gieson stain and tumor budding predicts local and distant metastases in patients with T1 stage colorectal cancer. Am J Surg Pathol 2009; 33: 1601-1607.

27. Kai K, Aishima S, Aoki S, et al. Cytokeratin immunohistochemistry improves interobserver variability between unskilled pathologists in the evaluation of tumor budding in T1 colorectal cancer. Pathol Int 2016; 66: 75-82.

28. Ohtsuki K, Koyama F, Tamura T, et al. Prognostic value of immunohistochemical analysis of tumor budding in colorectal carcinoma. Anticancer Res 2008; 28: 1831-1836.

29. Rieger G, Koelzer VH, Dawson HE, Berger MD, Hädrich M, Inderbitzin D, Lugli A, Zlobec I. Comprehensive assessment of tumour budding by cytokeratin staining in colorectal cancer. Histopathology 2017; 70: 1044-1051.

30. Okamura T, Shimada Y, Nogami H, Kameyama H, Kobayashi T, Kosugi S, Wakai T, Ajioka Y. Tumor Budding Detection by immuno histochemical staining is not Superior to hematoxylin and eosin staining for predicting lymph node metastasis in pT1 colorecta cancer. Dis Colon Rectum 2016; 59: 396-402.

31. Puppa G, Senore C, Sheahan K, et al. Diagnostic reproducibility of tumour budding in colorectal cancer: a multicentre, multinational study using virtual microscopy. Histopathology 2012; 61: 562-575.

32. Horcic M, Koelzer VH, Karamitopoulou E, Terracciano L, Puppa G, Zlobec I, Lugli A. Tumor budding score based on 10 high-power fields is a promising basis for a standardized prognostic scoring system in stage II colorectal cancer. Hum Pathol 2013; 44: 697705.

33. Koelzer VH, Dawson H, Andersson E, Karamitopoulou E1, Masucci GV2, Lugli A1, Zlobec I. Active immunosurveillance in the tumor microenvironment of colorectal cancer is associated with low frequency tumor budding and improved outcome. Transl Res 2015; 166: 207-217.

34. Shinto E, Mochizuki H, Ueno H, Matsubara O, Jass JR. A novel clas sification of tumour budding in colorectal cancer based on the presence of cytoplasmic pseudo-fragments around budding foci. Histopathology 2005; 47: 25-31.

35. Shinto E, Jass JR, Tsuda H, Sato T, Ueno H, Hase K, Mochizuki H, Matsubara O. Differential prognostic significance of morphologic invasive markers in colorectal cancer: tumor budding and cytoplasmic podia. Dis Colon Rectum 2006; 49: 1422-1430.

36. Prall F, Ostwald C. High-degree tumor budding and podia-formation in sporadic colorectal carcinomas with K-ras gene mutations. Hum Pathol 2007; 38: 1696-1702.

37. Prall F, Maletzki C, Hühns M, Krohn M, Linnebacher M. Colorectal carcinoma tumour budding and podia formation in the xenograft microenvironment. PLoS One 2017; 12: e0186271.

38. Prall F, Ostwald C, Linnebacher M. Tubular invasion and the morphogenesis of tumor budding in colorectal carcinoma. Hum Pathol 2009; 40: 1510-1512.

39. Jiang B, Mason J, Jewett A, Qian J, Ding Y, Cho WC, Zhang X, Man YG. Cell budding from normal appearing epithelia: a predictor of colorectal cancer metastasis? Int J Biol Sci 2013; 9: 119-133.

40. Ueno H, Price AB, Wilkinson KH, Jass JR, Mochizuki H, Talbot IC. A new prognostic staging system for rectal cancer. Ann Surg 2004; 240: 832-839.

41. Bronsert $P$, Enderle-Ammour K, Bader $M$, et al. Cancer cell invasion and EMT marker expression: a three-dimensional study of the human cancer-host interface. J Pathol 2014; 234: 410-422.

42. Choi HJ, Park KJ, Shin JS, Roh MS, Kwon HC, Lee HS. Tumor budding as a prognostic marker in stage-III rectal carcinoma. Int J Colorectal Dis 2007; 22: 863-868.

43. Masaki T, Matsuoka H, Sugiyama M, Abe N, Sakamoto A, Atomi Y. Actual number of tumor budding as a new tool for the individualization of treatment of T1 colorectal carcinomas. J Gastroenterol Hepatol 2006; 21: 1115-1121.

44. Homma Y, Hamano T, Otsuki Y, Shimizu S, Kobayashi H, Kobayashi Y. Severe tumor budding is a risk factor for lateral lymph node metastasis in early rectal cancers. J Surg Oncol 2010; 102: 230-234.

45. Ali AA, McMillan DC, Matalka II, McNicol AM, McArdle CS. Tumour T-lymphocyte subset infiltration and tumour recurrence following curative resection for colorectal cancer. Eur J Surg Oncol 2004, 30: 292-295.

46. Canna K, McArdle PA, McMillan DC, McNicol AM, Smith GW, Mckee RF, McArdle CS. The relationship between tumour T-lymphocyte infiltration, the systemic inflammatory response and survival in patients undergoing curative resection for colorectal cancer. Br J Cancer 2005; 92: 651-654.

47. Pages F, Berger A, Camus M, et al. Effector memory T cells, early metastasis, and survival in colorectal cancer. N Engl J Med 2005; 353: 2654-2666.

48. Lugli A, Karamitopoulou E, Panayiotides I, et al. CD8+ lymphocytes/ tumour-budding index: an independent prognostic factor representing a "pro-/anti-tumour" approach to tumour host interaction in colorectal cancer. Br J Cancer 2009; 101: 1382-1392.

49. Max N, Harbaum L, Pollheimer MJ, Lindtner RA3, Kornprat P4, Langner C. Tumour budding with and without admixed inflammation: two different sides of the same coin? Br J Cancer 2016; 114: 368-371.

50. van Wyk HC, Park JH, Edwards J, Horgan PG, McMillan DC, Going JJ. The relationship between tumour budding, the tumour microenvironment and survival in patients with primary operable colorectal cancer. Br J Cancer 2016; 115: 156-163.

51. Lugli A, Vlajnic T, Giger O, Karamitopoulou E, Patsouris ES, Peros G, Terracciano LM, Zlobec I. Intratumoral budding as a potential parameter of tumor progression in mismatch repair-proficient and 
mismatch repair-deficient colorectal cancer patients. Hum Pathol 2011; 42: 1833-1840.

52. Mitrovic B, Schaeffer DF, Riddell RH, Kirsch R. Tumor budding in colorectal carcinoma: time to take notice. Mod Pathol 2012; 25: 1315-1325.

53. Steinestel K, Lennerz JK, Eder S, Kraft K, Arndt A. Invasion pattern and histologic features of tumor aggressiveness correlate with MMR protein expression, but are independent of activating KRAS and BRAF mutations in CRC. Virchows Arch 2014; 465: 155-163.

54. Du C, Xue W, Li J, Cai Y, Gu J. Morphology and prognostic value of tumor budding in rectal cancer after neoadjuvant radiotherapy. Hum Pathol 2012; 43: 1061-1067.

55. Bhangu A, Wood G, Brown G, Darzi A, Tekkis P, Goldin R. The role of epithelial mesenchymal transition and resistance to neoadjuvant therapy in locally advanced rectal cancer. Colorectal Dis 2014; 16: 0133-143.

56. Guzińska-Ustymowicz K. The role of tumour budding at the front of invasion and recurrence of rectal carcinoma. Anticancer Res 2005; 25: 1269-1272.

57. Syk E, Lenander C, Nilsson PJ, Rubio CA, Glimelius B. Tumour bud ding correlates with local recurrence of rectal cancer. Colorectal Dis 2011; 13: 255-262.

58. Brabletz T, Jung A, Spaderna S, Hlubek F, Kirchner T. Migrating cancer stem cells - an integrated concept of malignant tumour progression. Nat Rev Cancer 2005; 5: 744-749.

59. Man YG, Shen T, Zhao YG, Amy Sang OX. Focal prostate basal cell layer disruptions and leukocyte infiltration are correlated events: A potential mechanism for basal cell layer disruptions and tumor invasion. Cancer Detect Prev 2005; 29: 161-169.

60. Man YG. Focal degeneration of aged or injured myoepithelial cells and the resultant auto-immunoreactions are trigger factors for breast tumor invasion. Med Hypoth 2007; 69: 1340-1357.

61. Man YG, Fu S, Liu AJ, Stojadinovic A, Izadjoo MJ, Chen L, Gardner WA. Aberrant expression of chromogranin A, mir-146a, and mir146b-5p in prostate structures with focally disrupted basal cell layers: an early sign of invasion and hormone-refractory cancer? Cancer Genomics Proteomics 2011; 8: 235-244.

62. Koliaraki V, Pallangyo CK, Greten FR, Kollias G. Mesenchymal Cells in Colon Cancer. Gastroenterology 2017; 152: 964-979.

63. Man YG, Mason J, Harley R, Kim YH, Zhu K, Gardner WA. Leuko cyte-facilitated tumor dissemination: findings from multiple types of human tumors. J Cell Biochem 2011; 112: 1154-1167.

64. Neeson PJ, Thurlow PJ, Jamieson GP, Bradley C. Lymphocyte-facilitated tumour cell adhesion to endothelial cells: the role of high affinity leucocyte integrins. Pathology 2003; 35: 50-55.

65. Masaki T, Goto A, Sugiyama M, Matsuoka H, Abe N, Sakamoto A, Atomi Y. Possible contribution of CD44 variant 6 and nuclear beta-catenin expression to the formation of budding tumor cells in patients with T1 colorectal carcinoma. Cancer 2001; 92: 2539 2546.

66. Jass JR, Barker M, Fraser L, Walsh MD, Whitehall VL, Gabrielli B, Young J, Leggett BA. APC mutation and tumour budding in col orectal cancer. J Clin Pathol 2003; 56: 69-73.

67. El-Gendi S, Al-Gendi A. Assessment of tumor budding in colorectal carcinoma: correlation with -catenin nuclear expression. J Egypt Natl Canc Inst 2011; 23: 1-9.

68. Kevans D, Wang LM, Sheahan K, Hyland J, O'Donoghue D, Mulca hy H, O'Sullivan J. Epithelial-mesenchymal transition (EMT) protein expression in a cohort of stage II colorectal cancer patients with characterized tumor budding and mismatch repair protein status. Int J Surg Pathol 2011; 19: 751-760.

69. Kobayashi M, Honma T, Matsuda Y, Suzuki Y, Narisawa R, Ajioka Y, Asakura $\mathrm{H}$. Nuclear translocation of beta-catenin in colorectal cancer. Br J Cancer 2000; 82: 1689-1693.

70. Kalluri R, Weinberg RA. The basics of epithelial-mesenchyma transition. J Clin Invest 2009; 119: 1420-1428.

71. Scheel C, Weinberg RA. Cancer stem cells and epithelial-mesenchymal transition: concepts and molecular links. Semin Cancer Biol 2012; 22: 396-403.

72. Cui G, Shi Y, Cui J, Tang F, Florholmen J. Immune microenvironmental shift along human colorectal adenoma-carcinoma sequence: is it relevant to tumor development, biomarkers and biotherapeutic targets? Scand J Gastroenterol 2012; 47: 367-377.

73. De Smedt L, Palmans S, Andel D, et al. Expression profiling of budding cells in colorectal cancer reveals an EMT-like phenotype and molecular subtype switching. Br J Cancer 2017; 116: 58-65.

74. Guzińska-Ustymowicz K, Zalewski B, Kasacka I, Piotrowski Z, Skrzydlewska E. Activity of cathepsin B and D in colorectal cancer: relationships with tumour budding. Anticancer Res 2004; 24: 2847-2851.

75. Lah TT, Kalman E, Najjar D, orodetsky E, Brennan P, Somers R, Daskal I. Cells producing cathepsins D, B, and L in human breast carcinoma and their association with prognosis. Hum Pathol 2000; 31: 149-160.

76. Hazen LGM, Bleeker FE, Lauritzen B, et al. Comparative localization of cathepsin B protein and activity in colorectal cancer. J Histochem Cytochem 2000; 48: 1421-1430.

77. Khan A, Krishna M, Baker S, Banner BF. Cathepsin B and tumor-associated laminin expression in the progression of colorectal adenoma to carcinoma. Mod Pathol 2004; 11: 704-708.

78. Yusra M, Semba S, Yokozaki H. Biological significance of tumor budding at the invasive front of human colorectal carcinoma cells. Int J Oncol 2012; 41: 201-210.

79. Emmert-Buck MR, Roth MJ, Zhuang Z, Campo E, Rozhin J, Sloane BF, Liotta LA, Stetler-Stevenson WG. Increased gelatinase A(MMP-2) and cathepsin B activity in invasive tumour regions of human colon cancer samples. Am J Pathol 1994; 45: 1285-1290.

80. Jung A, Schrauder M, Oswald U, et al. The invasion front of human colorectal adenocarcinomas shows co-localization of nuclear beta-catenin, cyclin D1, and p16INK4A and is a region of low proliferation. Am J Pathol 2001; 159: 1613-1617.

81. Zlobec I, Bihl MP, Foerster A, Rufle A, Lugli A. The impact of CpG island methylator phenotype and microsatellite instability on tumour budding in colorectal cancer. Histopathology 2012; 61: 777-787.

82. Jervoise H, Andreyev HJN, Norman AR, Oates JR, Clarke PA. Kirsten ras mutations in patients with colorectal cancer: the multicenter "RASCAL" study. J Natl Cancer Inst 1998; 90: 675-684.

83. Andreyev HJN, Norman AR, Cuningham D, et al. Kirsten ras mutations in patients with colorectal cancer: the "RASCAL II" study. Br J Cancer 2001; 85: 692-696.

84. Rubio CA. Arrest of cell proliferation in budding tumor cells ahead of the invading edge of colonic carcinomas. A preliminary report. Anticancer Res 2008; 28: 2417-2420.

85. Dawson H, Koelzer VH, Karamitopoulou E, Economou M, Hammer C, Muller DE, Lugli A, Zlobec I. The apoptotic and proliferation rate of tumour budding cells in colorectal cancer outlines a heterogeneous population of cells with various impacts on clinical outcome. Histopathology 2014; 64: 577-584

86. Zlobec I, Lugli A, Baker K, Roth S, Minoo P, Hayashi S, Terracciano L, Jass JR. Role of APAF-1, E-cadherin and peritumoral lymphocytic infiltration in tumour budding in colorectal cancer. J Pathol 2007; 212: 260-268.

87. Guzińska-Ustymowicz K, Sulkowska M, Famulski W, Sulkowski S. Tumour "budding" and its relationship to p53 and Bcl-2 expression in colorectal cancer. Anticancer Res 2003; 23: 649-653.

88. Karamitopoulou E, Lugli A, Panayiotides I, et al. Systematic assessment of protein phenotypes characterizing high-grade tumour budding in mismatch repair-proficient colorectal cancer. Histopathology 2010; 57: 233-243.

89. Frisch SM, Ruoslahti E. Integrins and anoikis. Curr Opin Cell Biol 1997; 9: 701-706.

90. Frisch SM, Screaton RA. Anoikis mechanisms. Curr Opin Cell Biol 2001; 13: 555-562.

91. Khanh do T, Mekata E, Mukaisho K, et al. Prognostic role of CD10 myeloid cells in association with tumor budding at the invasion front of colorectal cancer. Cancer Sci 2011; 102: 1724-1733.

92. Yu Q, Stamenkovic I. Cell surface-localized matrix metalloproteinase-9 proteolytically activates TGF-beta and promotes tumor invasion and angiogenesis. Genes Dev 2000; 14: 163-176.

93. Gurzu S, Banias L, Kovacs Z, Jung I. Epithelial-mesenchymal transition of tumor budding in colorectal cancer: the mystery of 
CD44-positive stromal cells. Hum Pathol (in press). doi: 10.1016/j. humpath.2017.07.019.

94. Khanh do T, Mekata E, Mukaisho K, et al. Transmembrane mucin MUC1 overexpression and its association with CD10 myeloid cells, transforming growth factor- $\beta 1$ expression, and tumor budding grade in colorectal cancer. Cancer Sci 2013; 104: 958-964.

95. Righi A, Sarotto I, Casorzo L, Cavalchini S, Frangipane E, Risio M. Tumour budding is associated with hypoxia at the advancing front of colorectal cancer. Histopathology 2015; 66: 982-990.

96. Khanh do T, Mekata E, Mukaisho K, et al. Myeloid cells positive for CD10 at invasion front can predict poor outcome in stage II colorectal cancer. Int J Clin Oncol 2012; 17: 240-249.

97. Caie PD, Turnbull AK, Farrington SM, Oniscu A, Harrison DJ. Quantification of tumour budding, lymphatic vessel density and in vasion through image analysis in colorectal cancer. J Transl Med 2014; $12: 156$.

98. Mezheyeuski A, Nerovnya A, Bich T, Tur G, Ostman A, Portyanko A. Inter- and intra-tumoral relationships between vasculature characteristics, GLUT1 and budding in colorectal carcinoma. Histol Histopathol 2015; 30: 1203-1211

99. Xu CJ, Mikami T, Nakamura T, Tsuruta T, Nakada N, Yanagisawa N, Jiang SX, Okayasu I. Tumor budding, myofibroblast proliferation, and fibrosis in obstructing colon carcinoma: the roles of $\mathrm{Hsp} 47$ and basic fibroblast growth factor. Pathol Res Pract 2013; 209 69-74.

100. Knudsen KN, Lindebjerg J, Nielsen BS, Hansen TF, Sørensen FB. MicroRNA-200b is down-regulated in colon cancer budding cells. PLoS One 2017; 12: e0178564.

101. Baltruskeviciene E, Schveigert D, Stankevicius V, Mickys U, Zvirblis T, Bublevic J, Suziedelis K, Aleknavicius E. Down-regulation of miRNA-148a and miRNA-625-3p in colorectal cancer is associated with tumor budding. BMC Cancer 2017; 17: 607.

102. Roh MS, Lee JI, Choi PJ. Tumor budding as a useful prognostic marker in esophageal squamous cell carcinoma. Dis Esophagus 2004; 17: 333-337.

103. Koike M, Kodera Y, Itoh Y, Nakayama G, Fujiwara M, Hamajima N, Nakao A. Multivariate analysis of the pathologic features of esophageal squamous cell cancer: Tumor budding is a significant independent prognostic factor. Ann Surg Oncol 2008; 15: 19771982.

104. Masugi Y, Yamazaki K, Hibi T, Aiura K, Kitagawa Y, Sakamoto M. Solitary cell infiltration is a novel indicator of poor prognosis and epithelial-mesenchymal transition in pancreatic cancer. Hum Pathol 2010; 41: 1061-1068.

105. O'Connor K, Li-Chang HH, Kalloger SE, et al. Tumor budding is an independent adverse prognostic factor in pancreatic ductal adenocarcinoma. Am J Surg Pathol 2015; 39: 472-478.

106. Chouat E, Zehani A, Chelly I, et al. Tumor budding is a prognostic factor linked to epithelial mesenchymal transition in pancreatic ductal adenocarcinoma. Study report and literature review. Pancreatology 2018; 18: 79-84.

107. Taira T, Ishii G, Nagai K, et al. Characterization of the immunophenotype of the tumor budding and its prognostic implications in squamous cell carcinoma of the lung. Lung Cancer 2012;76: 423-430.

108. Liang F, Cao W, Wang Y, Li L, Zhang G, Wang Z. The prognostic value of tumor budding in invasive breast cancer. Pathol Res Pract 2013; 209: 269-275.

109. Almangush A, Salo T, Hagström J, Leivo I. Tumour budding in head and neck squamous cell carcinoma - a systematic review. Histopathology 2014; 65: 587-594.

\section{Address for correspondence}

Leonardo S. Lino-Silva

National Cancer Institute

Av. San Fernando 22 col. Sección XV

14080 Mexico City, Mexico

e-mail:saul.lino.sil@gmail.com

Submitted: 18.03 .2018

Accepted: $\quad 3.04 .2018$ 


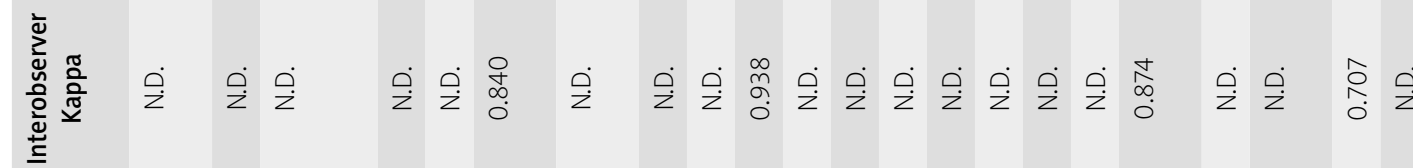

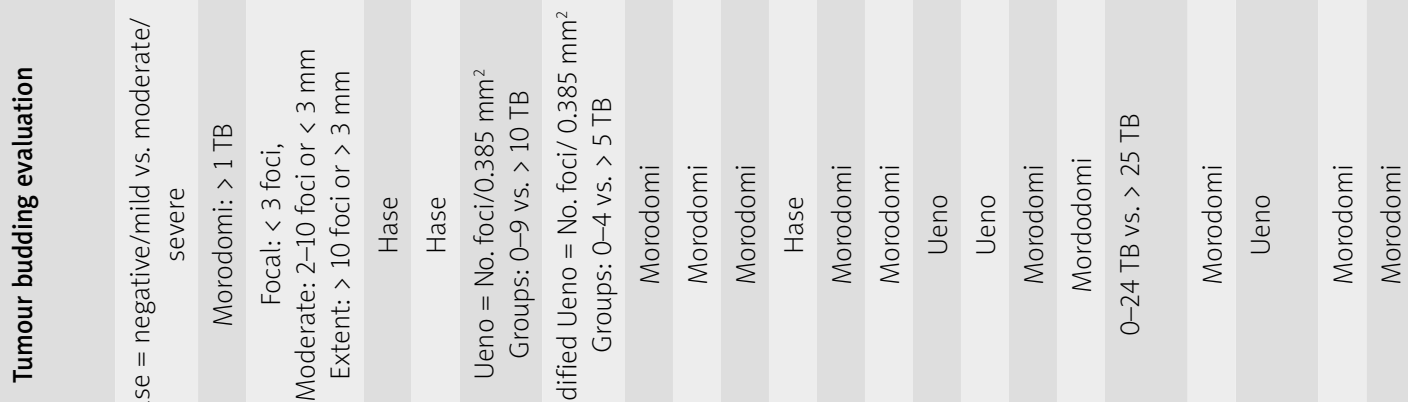

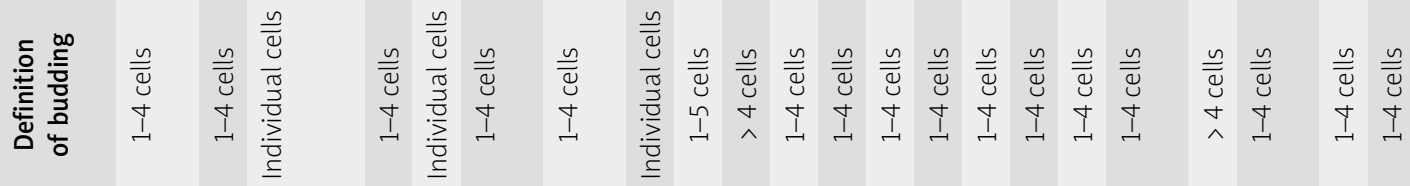

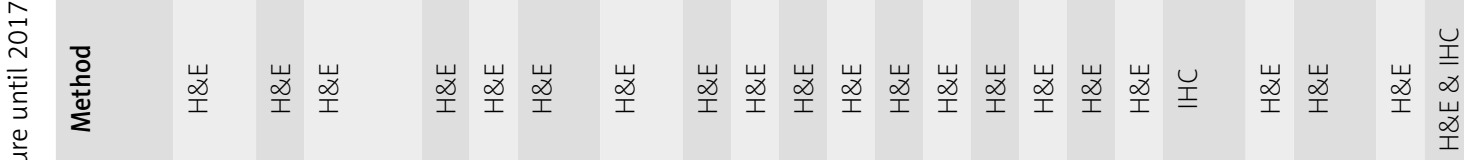

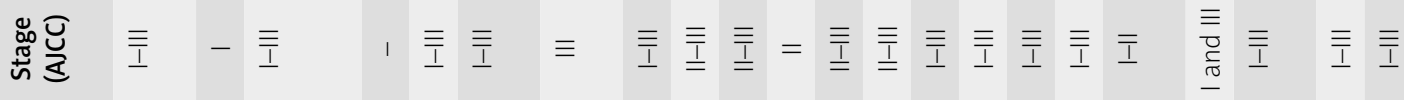

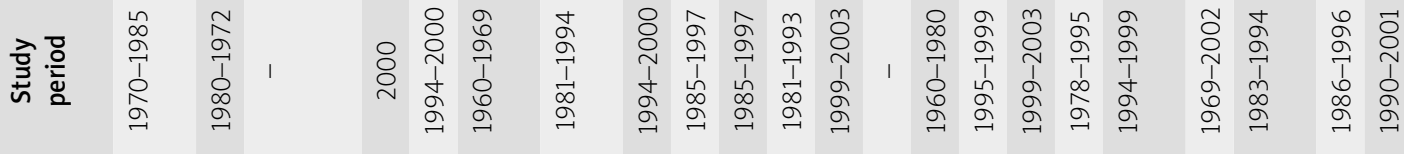

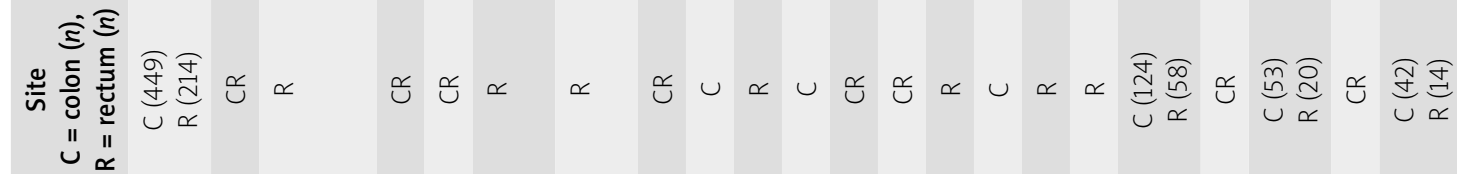

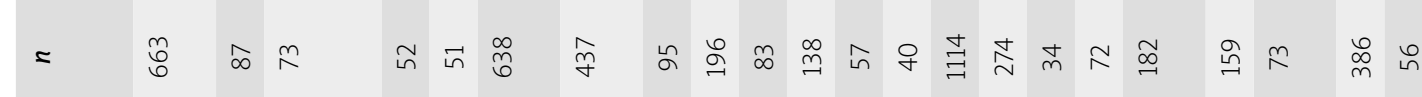

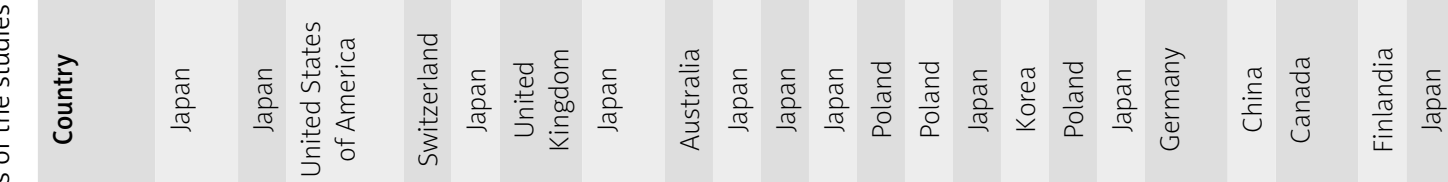

气

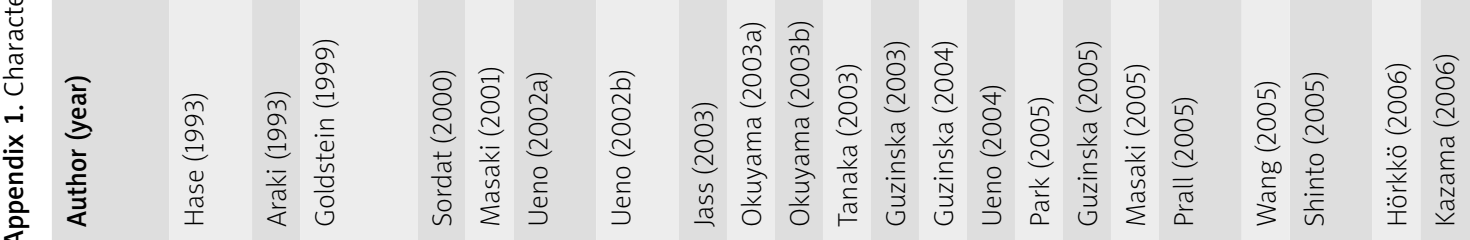


|

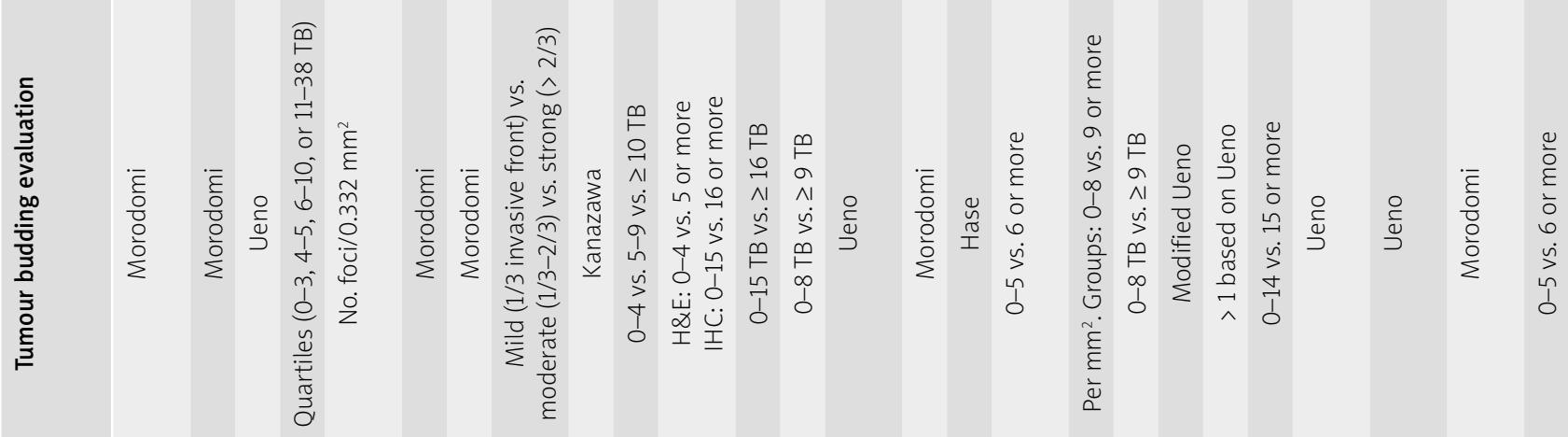

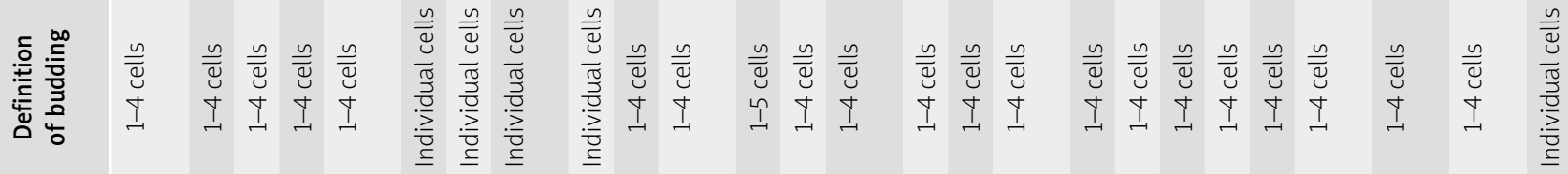

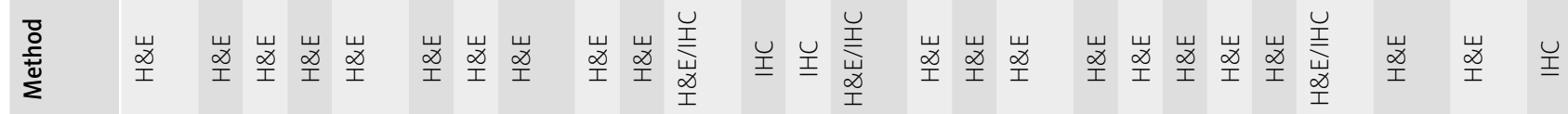

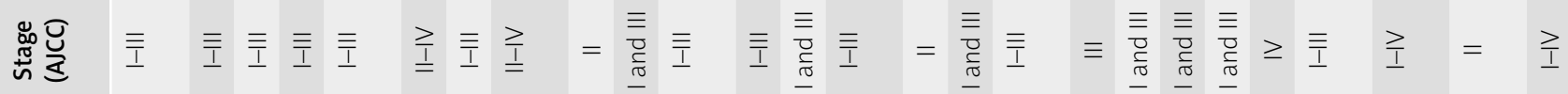

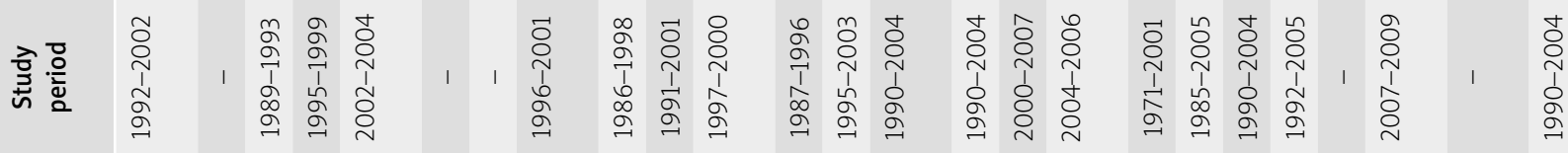

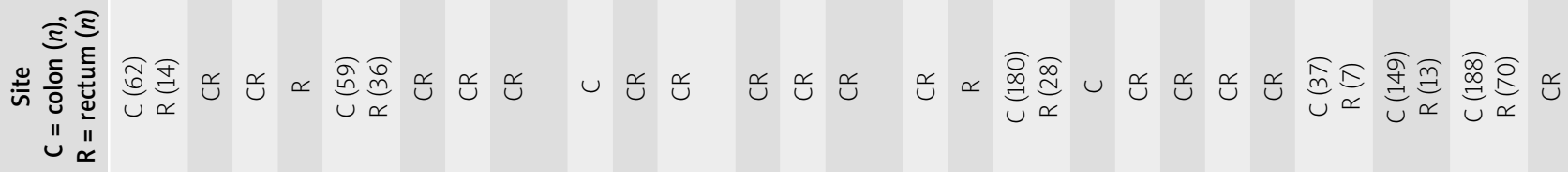

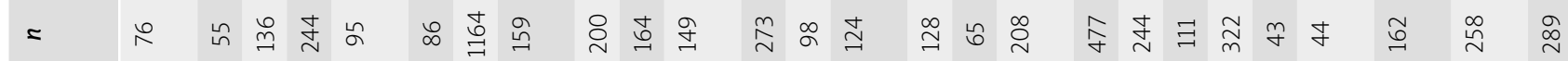

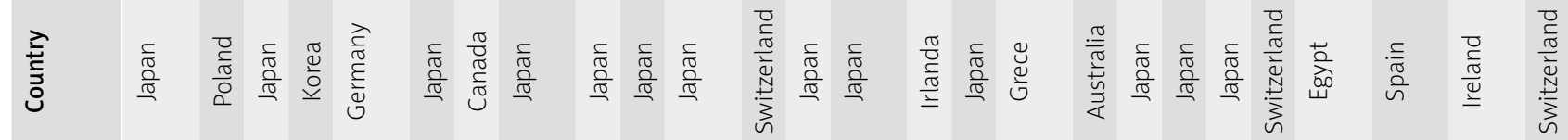

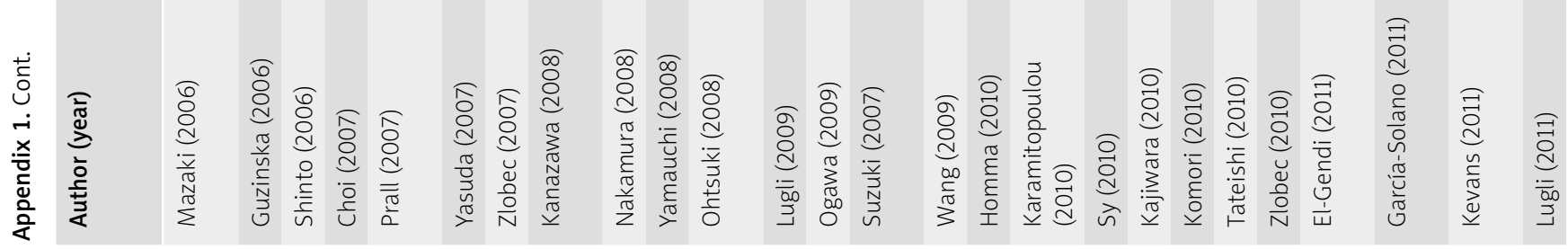


If

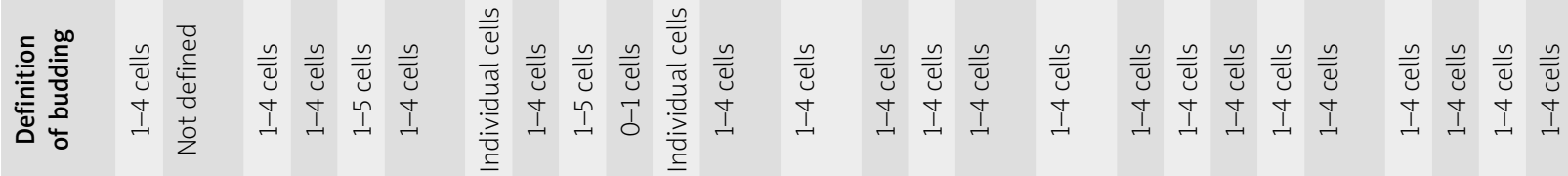

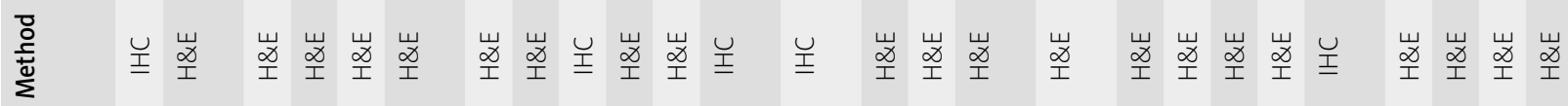

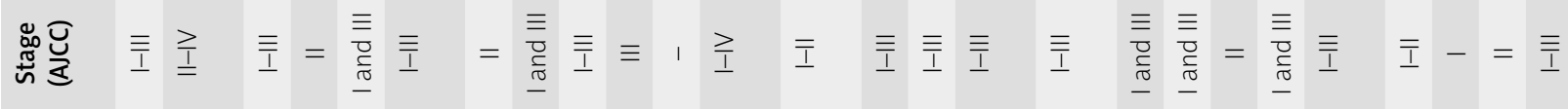

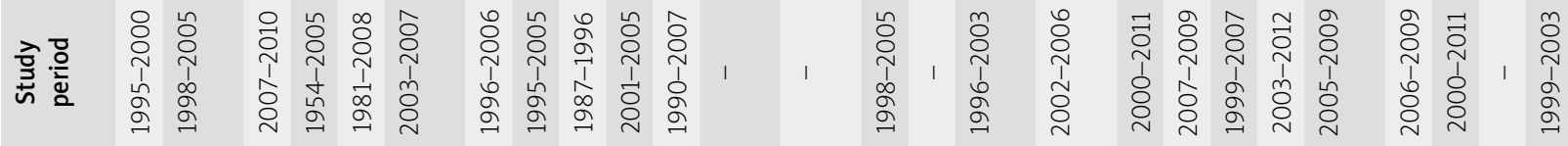

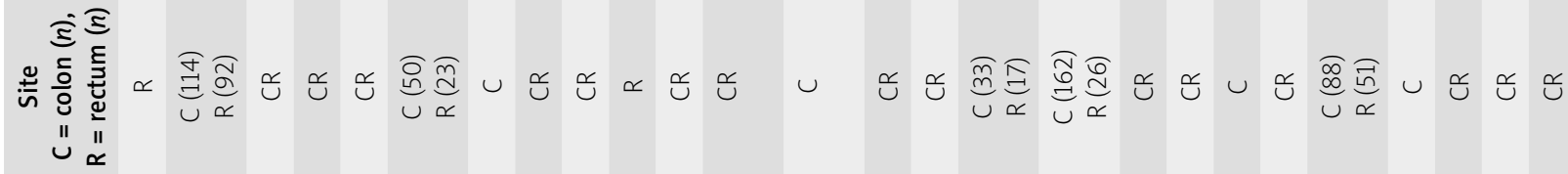

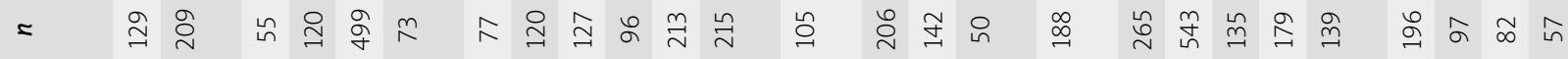

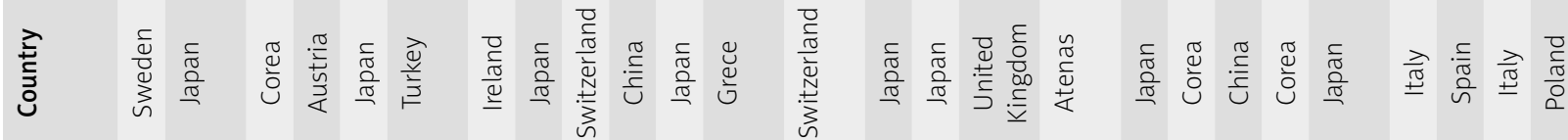

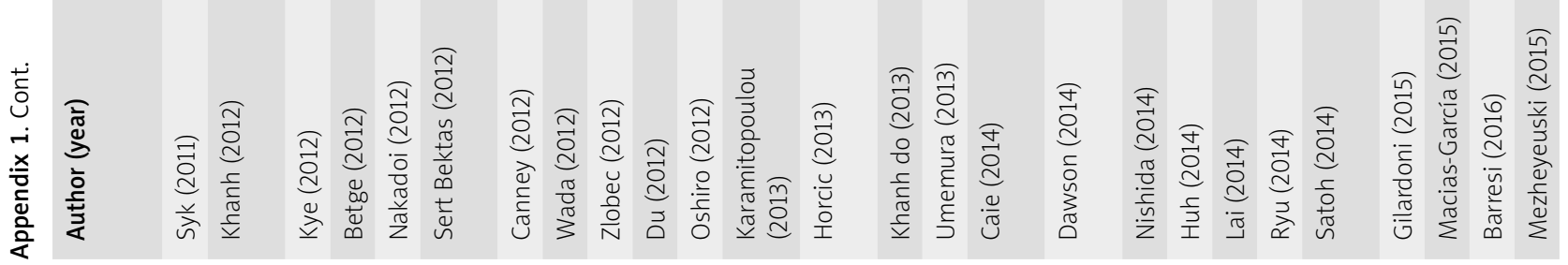




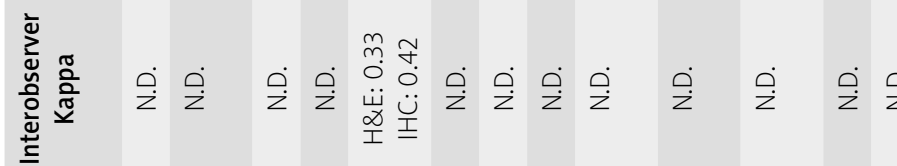

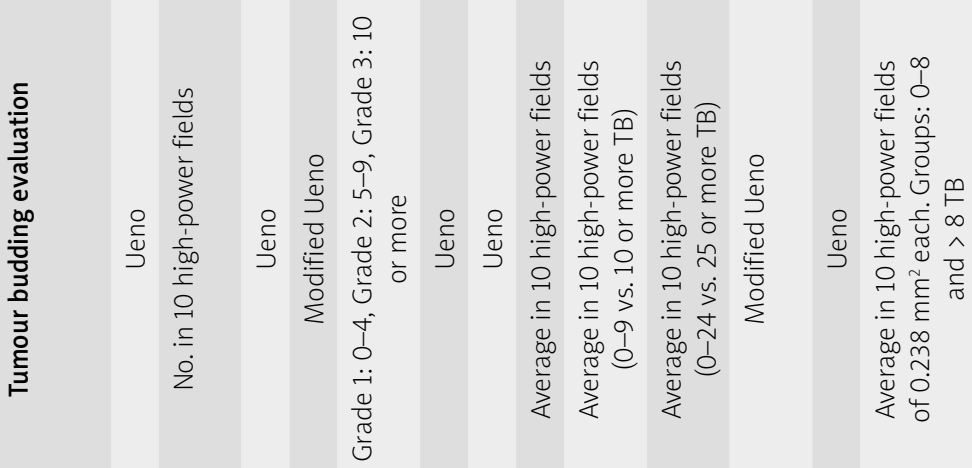

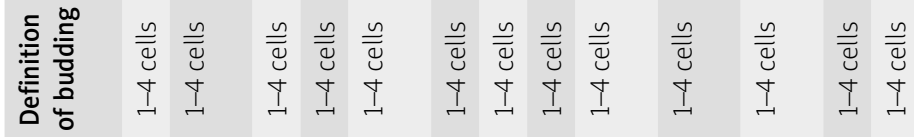

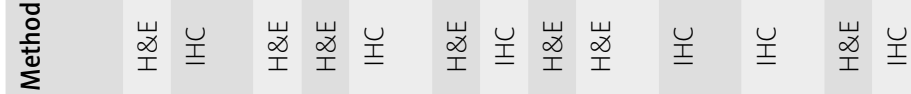

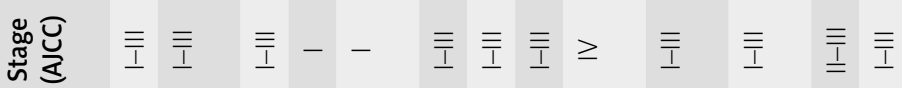

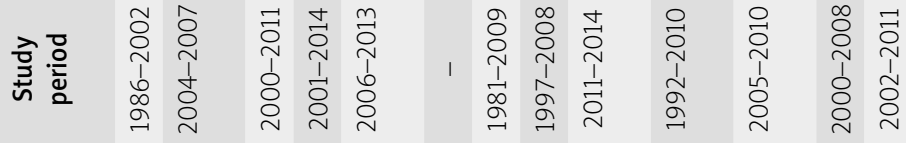

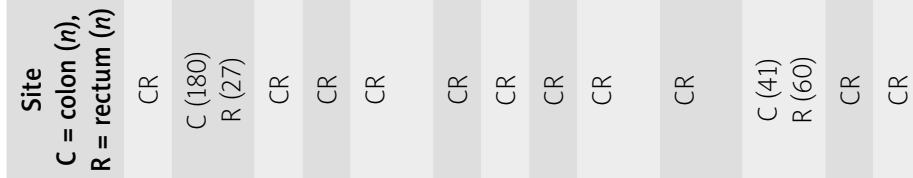

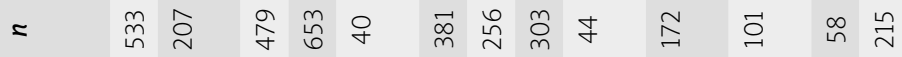

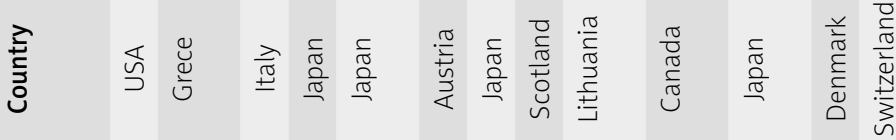

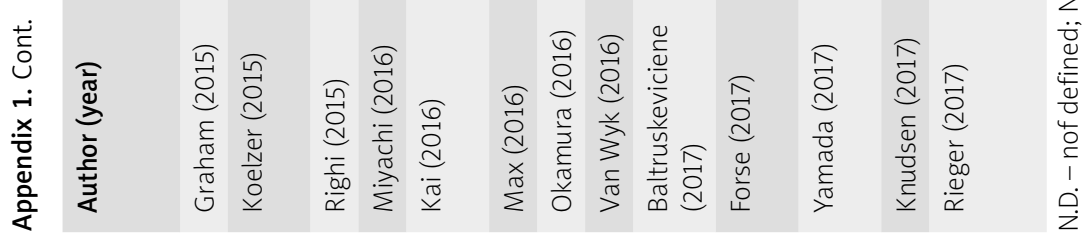

